NBER WORKING PAPER SERIES

\title{
THE IMPACT OF INCREASED UTILIZATION OF HIV DRUGS ON LONGEVITY AND MEDICAL EXPENDITURE: AN ASSESSMENT BASED ON AGGREGATE U.S. TIME-SERIES DATA
}

\author{
Frank R. Lichtenberg \\ Working Paper 12406 \\ http://www.nber.org/papers/w12406
NATIONAL BUREAU OF ECONOMIC RESEARCH
1050 Massachusetts Avenue
Cambridge, MA 02138
July 2006

This research was supported by Abbott Laboratories, which develops and manufactures some HIV drugs. The publication of study results was not contingent on the sponsor's approval or censorship of the manuscript. The views expressed herein are those of the author(s) and do not necessarily reflect the views of the National Bureau of Economic Research.

(C2006 by Frank R. Lichtenberg. All rights reserved. Short sections of text, not to exceed two paragraphs, may be quoted without explicit permission provided that full credit, including () notice, is given to the source. 
The Impact of Increased Utilization of HIV Drugs on Longevity and Medical Expenditures: An Assessment Based on Aggregate U.S. Time-Series Data

Frank R. Lichtenberg

NBER Working Paper No. 12406

July 2006

JEL No. I12, J1, O33

\begin{abstract}
$\underline{\text { ABSTRACT }}$
We estimate the medical cost per life-year gained from increased utilization of HIV drugs by estimating the impact of increased drug utilization on the life expectancy and drug and hospital expenditure of HIV/AIDS patients, using aggregate (U.S. national-level) data for the period 1982-2001. We use IMS Health data on the aggregate number of and expenditure on HIV drug prescriptions, the CDC's AIDS Public Information Data Set, and data from AHRQ's Nationwide Inpatient Sample.

Estimates of mortality models imply that actual life expectancy of HIV/AIDS patients in 2001 was 13.4 years higher than it would have been if the drug utilization rate had not increased from its 1993 level. Estimates of a model of hospital discharges imply that increased utilization of HIV drugs caused hospital utilization to decline by .25 to .29 discharges per person per year during the period 1993-2001. Medical cost per additional life-year is estimated to have been $\$ 17,175$.

Treatments that cost this amount are widely considered to be cost-effective. The consistency of this estimate with those from previous studies suggests that analysis of aggregate data may be a useful alternative or additional approach to evaluating the cost-effectiveness of new treatments.
\end{abstract}

Frank R. Lichtenberg

Graduate School of Business

Columbia University

614 Uris Hall

3022 Broadway

New York, NY 10027

and NBER

$\underline{\text { frl1@ columbia.edu }}$ 


\section{Introduction}

Between 1993 and 2000, inflation-adjusted expenditure on HIV drugs per person living with AIDS increased more than fivefold, from about $\$ 1700$ to about $\$ 9000$. This was largely attributable to substantial HIV drug innovation during this period: the number of FDA-approved HIV drug classes tripled (from 1 to 3), and the number of FDA-approved HIV drugs increased from 3 to $17[1]$.

We will show that, during the same period, the number of hospital admissions for HIV infection per person living with AIDS declined 67\%, and the five-year survival rate of people diagnosed with AIDS increased from 3\% to 54\%. How much of the decline in the hospitalization rate, and increase in the survival rate, can be attributed to the large increase in HIV drug utilization? To determine the incremental cost-effectiveness of these drugs, we need answers to these questions.

Previous studies have used a variety of methods to estimate the clinical benefits and cost effectiveness of HIV/AIDS drugs. Freedberg et al [2] developed a mathematical simulation model of HIV disease, using the CD4 cell count and HIV RNA level as predictors of the progression of disease. They derived clinical data from major clinical trials, including the AIDS Clinical Trials Group 320 Study, and data on costs from the national AIDS Cost and Services Utilization Survey and the Red Book. They found that for patients similar to those in the AIDS Clinical Trials Group 320 Study (mean CD4 cell count, 87 per cubic millimeter), life expectancy adjusted for the quality of life increased from 1.53 to 2.91 years, and per-person lifetime costs increased from $\$ 45,460$ to $\$ 77,300$ with three-drug therapy as compared with no therapy. The incremental cost per quality-adjusted year of life gained, as compared with no therapy, was $\$ 23,000$. On the basis of additional data from other major studies, the cost-effectiveness ratio for three-drug therapy ranged from $\$ 13,000$ to $\$ 23,000$ per quality-adjusted year of life gained. They 
concluded that treatment of HIV infection with a combination of three antiretroviral drugs is a cost-effective use of resources.

Duggan and Evans [3] used individual-level pharmacy and medical claims data on about 10,000 California Medicaid recipients diagnosed with HIV/AIDS to estimate the effect of HIV antiretroviral (ARV) treatments on longevity and long-term health care spending during the period 1993-2003. Approximately half of all AIDS patients in the U.S. are enrolled in Medicaid. They accounted for the fact that patients taking ARVs are significantly less healthy than the average patient in their sample. Their findings demonstrated that the increase in the use of four drugs approved by the FDA in late 1995 and early 1996 was responsible for more than 90 percent of the drop in the mortality rate from 1995 to 1998 . Despite the entry of more than a dozen drugs since these four, mortality rates have remained virtually unchanged. They found that the use of the new drugs led to a threefold increase in lifetime Medicaid spending due to their high cost and the resulting increase in life expectancy. Despite this, the new treatments were cost-effective, with the average additional cost in Medicaid spending per life-year saved equal to $\$ 23,000$.

In this paper, we use a third approach to estimate the clinical benefits and cost effectiveness of HIV/AIDS drugs: estimation of econometric models of mortality and hospitalization rates of HIV/AIDS patients using aggregate (U.S. national-level) time-series data for the period 1981-2001.

\section{Methods}

We will estimate the relationship in the population of HIV/AIDS patients between the HIV drug utilization rate and both (1) the mortality rate and (2) the HIV hospitalization rate. First we will explain how these three variables were measured. Then we will specify the relationships to be estimated. 
Mortality rate. The mortality rate is the number of deaths in a period divided by the average number of people alive during the period. It can be estimated during the period 1981-2001 from the CDC's AIDS Public Information Data Set [4]. AIDSPIDS contains two types of data: micro and macro. The micro data set contains one record for each AIDS case reported to CDC during the period 1981-2001. It reports the month of diagnosis of the person's first AIDS-indicator opportunistic condition. It also indicates whether the CDC was notified that this patient died by the end of 1999, but to protect confidentiality, it does not report the date of death.

The macro data set provides frequencies of AIDS cases, by period (half-year) of diagnosis and period of death. For example, it reveals that 264 people diagnosed with AIDS in the first half of 1988 died in the second half of 1992.

The CDC expanded its AIDS surveillance definition on January 1, 1993 to include all HIVinfected adults and adolescents who had less that $200 \mathrm{CD}^{+} \mathrm{T}$-lymphocytes/ $\mu \mathrm{L}$ or a $\mathrm{CD} 4^{+} \mathrm{T}$ lymphocyte percent of total lymphocytes less than 14, or who have been diagnosed with pulmonary tuberculosis, invasive cervical cancer, or recurrent pneumonia [5]. This revision had a substantial impact on the number of reported cases: the number of reported cases increased from 47,293 in 1992 to 104,759 in 1993 . But to measure trends over time using a constant case definition, CDC developed methods that estimated incidence of 1987 or 1993 definition opportunistic infections for cases that met only the 1993 immunologic $\left(C D 4^{+}\right)$criteria. As a result, the 1993 expansion of the AIDS case definition had only a small, transitory effect on the estimated number of diagnosed cases: the number of diagnosed cases was 79,657 in 1992 and 79,879 in 1993.

Let

N_DIAG ${ }_{j}=$ the number of people first diagnosed with AIDS in year $\mathrm{j}$

N_DIED ${ }_{j}=$ the number of deaths from AIDS in year $\mathrm{j}$

These data allow us to calculate the number of AIDS patients alive at the beginning of period $t$ $\left(\mathrm{N}_{-} \mathrm{ALIVE}_{\mathrm{t}}\right)$ and the mortality rate during period $\mathrm{t}\left(\mathrm{MORT} \_\right.$RATE $\left.\mathrm{t}\right)$, as follows: 


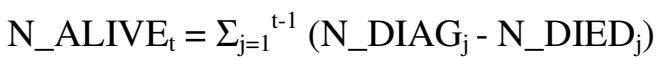

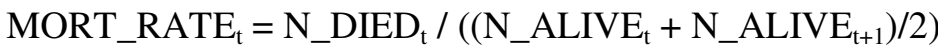

The top part of Figure 1 displays data on the AIDS mortality rate. We computed the annual mortality rate from semiannual data as follows: $\mathrm{a}=\left(1-(1-\mathrm{s})^{2}\right)$, where a denotes the annual mortality rate and s denotes the semiannual mortality rate.

The CDC [6] publishes data on the U.S. HIV/AIDS mortality rate; Lai et al [7] used these data to compute the potential gains of life expectancy due to the elimination or reduction of HIV/AIDS deaths. The CDC's HIV/AIDS mortality rate (CDC_RATE) is defined as follows:

CDC_RATE $=$ N_DIED $/$ POP

where $\mathrm{POP}=$ population. The CDC's mortality rate (the unconditional probability of dying from HIV/AIDS) is the product of two variables: the probability of dying from HIV/AIDS, conditional on having HIV/AIDS, and the probability of having HIV/AIDS:

CDC_RATE $=($ N_DIED / PREV $) *(P R E V / P O P)$

$=$ MORT_RATE $*(\mathrm{PREV} / \mathrm{POP})$

where $\operatorname{PREV}_{\mathrm{t}}=\left(\mathrm{N} \_\mathrm{ALIVE} \mathrm{t}_{\mathrm{t}}+\mathrm{N} \_\mathrm{ALIVE} \mathrm{t}_{\mathrm{t}+1}\right) / 2$.

Since we want to examine the relationship between the HIV drug utilization rate and the mortality rate in the population of HIV/AIDS patients, we will analyze data on the conditional mortality rate (MORT_RATE), rather than on the CDC's unconditional mortality rate.

The lower part of Figure 1 displays data on the percentage change in the AIDS mortality rate. Before 1987, when the first HIV drug was introduced, the mortality rate was in the $60-70 \%$ range, and was not declining. From the first half of 1987 to the second half of 1995, it declined at the rate of $6.1 \%$ per half year. From the second half of 1995 to the first half of 1998 , it declined four times as rapidly--at the rate of $24.8 \%$ per half year. From the first half of 1998 to the first half of 2001, it declined less rapidly--at the rate of $9.0 \%$ per half year. 
We compared mortality rates in 1994, 1997, and 2000 derived from AIDSPIDS with corresponding rates reported by Duggan and Evans [3, Table 2] from the California Medicaid sample. The mortality rates in 2000 differ by only $10 \%$, and both series indicate much more rapid decline during 1994-1997 than during 1997-2000. However, the AIDSPIDS series exhibits more rapid decline: the ratio of the 1994 to the 2000 mortality rate is 6.25 for AIDPIDS, vs. 4.42 for the California Medicaid sample.

Survival functions for 1993 and 2000 are depicted in Figure 2. They demonstrate the dramatic reduction in mortality during the 1990s.

The average age of people diagnosed with AIDS tended to increase over time. Before 1985, over half of people diagnosed were under 35. After 1999, less than $30 \%$ of people diagnosed were under 35 . In general, mortality rates increase with age, so the increase in age at diagnosis may make the decline in mortality even more striking. However, it is possible that the disease progresses less rapidly in older patients than it does in younger patients, so the decline in the age-adjusted mortality rate could be smaller than the decline in the crude mortality rate. Although we have time-series data on the age distribution of people diagnosed with AIDS, we do not have data on the age distribution of people living with AIDS, so we can't make an explicit adjustment for this. However, the data indicate that the age distribution of people diagnosed with AIDS shifted at a fairly steady rate, so the estimation procedure we will use (described below), which involved first-differencing the data, may adequately control for the effect of changes in the age distribution of people living with AIDS.

Life expectancy. Our goal is to assess the impact of changing HIV drug utilization on the life expectancy of HIV/AIDS patients. The concept of life expectancy we use is the one used by the National Center for Health Statistics [8] to calculate the official government estimates of U.S. life expectancy. It is based on the "period life-table" (as opposed to the "cohort life-table") method. The period life table presents what would happen to a hypothetical (or synthetic) cohort if it experienced throughout its entire life the mortality conditions of a particular period in time. 
The period life table renders a "snapshot" of current mortality experience, and shows the longrange implications of a set of duration-specific death rates that prevailed in a given year.

Under certain assumptions, there is a very simple relationship between life expectancy and the crude mortality rate. If the survival distribution function is exponential, i.e. the hazard rate is independent of duration, life expectancy is simply the reciprocal of the crude mortality rate. For example, if the crude mortality rate is $5 \%$, then life expectancy is 20 years.

Analysis of the AIDSPIDS data revealed that the hazard rate is not independent of duration: the hazard rate is strictly decreasing with respect to duration of illness. For example, a person is $17 \%$ less likely to die in the third year after diagnosis than in the first year after diagnosis, and is $35 \%$ less likely to die in the fifth year than in the first year. This may be partly or wholly attributable to heterogeneous severity of (or vulnerability to) illness: individuals with less severe cases are both more likely to survive until the beginning of year $\mathrm{t}$, and less likely to die during year $\mathrm{t}$, conditional on survival until the beginning of year $\mathrm{t}$. We therefore also computed estimates of life expectancy from survival functions that are more flexible than the exponential (e.g. the Weibull or the Gamma). We found that these estimates of life expectancy were fairly similar to those produced by the much simpler approach (i.e. computing the reciprocal of the mortality rate), despite evidence that the hazard rate is not independent of duration. Therefore, like Duggan and Evans [3], we will estimate life expectancy by the reciprocal of the mortality rate:

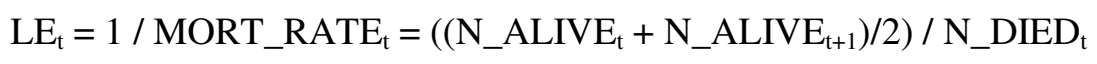

Drug utilization rate. The drug utilization rate $\left(\mathrm{rx}_{\mathrm{t}}\right)$ is the ratio of the number of prescriptions (Rx's) for HIV drugs to the number of people living with AIDS.

$$
\begin{aligned}
\mathrm{rx}_{\mathrm{t}} & =\mathrm{N}_{-} \mathrm{RX}_{\mathrm{t}} /\left(\left(\mathrm{N} \_\mathrm{ALIVE}_{\mathrm{t}}+\mathrm{N} \_\mathrm{ALIVE}\right.\right. \\
\mathrm{t}+1 & ) / 2) \\
& =\text { HIV rx's per person living with AIDS in period } \mathrm{t}
\end{aligned}
$$

where N_RX $\mathrm{t}_{\mathrm{t}}=$ the number of prescriptions (Rx's) for HIV drugs in period t. (This refers to any prescription during the time period considered (i.e., consecutive as well as simultaneous)). 
Data on the numerator of this ratio were obtained from IMS Health. Different purchasers incur different expenditures for the same drug in the U.S. This is particularly true for HIV drugs, where the major payers are state Medicaid and AIDS Drug Assistance Programs, who receive substantial receive discounts and manufacturer rebates. These discounts and rebates are reflected in the IMS data: the data reflect actual transaction prices, not list prices such as "average wholesale price".

Data on the denominator were computed from AIDSPIDS. Data on HIV drug expenditure, quantities, and prices, 1987-2003, are shown in Table 1. Figure 3 shows average drug utilization during the period 1981-2001. No HIV drugs were consumed (or approved) until 1987. From 1987 to 1992, the number of HIV Rx's per person increased steadily, reaching about 3.7 per half-year in 1992. From 1992 to 1995 , average drug utilization declined, to about 2.2 HIV Rx's per half-year. From the second half of 1995 to the second half of 1997, average drug utilization quadrupled, from 2.55 to 10.29 per half-year. Despite the FDA approval of five new drugs during 1998-2000, it stayed close to ten through the first half of 2001.

Hospitalization rate. We obtained annual data on inpatient hospitalizations for HIV infections during the period 1993-2002 from the Nationwide Inpatient Sample (NIS). NIS is the largest all-payer inpatient care database in the United States. It contains data from approximately 7 million hospital stays. NIS is the only national hospital database with charge information on all patients, regardless of payer, including persons covered by Medicare, Medicaid, private insurance, and the uninsured. NIS 2002 contains all discharge data from 995 hospitals located in 35 States, approximating a 20-percent stratified sample of U.S. community hospitals. NIS data are available from 1988 to 2002, and HCUP publishes state- and national-level data for the period 1993-2002. The number of States in the NIS has grown from 8 in the first year to 35 currently.

Data on inpatient hospitalizations for HIV infections (Major Diagnostic Category 25) during the period 1993-2002 were downloaded directly from the HCUPnet website [9] and are presented in Table 2. We defined the HIV hospitalization rate as follows: 


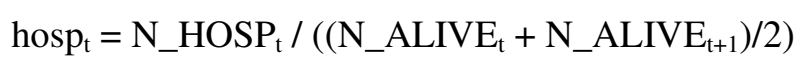

= inpatient hospital discharges for HIV infections per person living with AIDS in year $\mathrm{t}$

where $\mathrm{N} \_\mathrm{HOSP}_{\mathrm{t}}=$ the number of inpatient hospitalizations for HIV infections in period $\mathrm{t}$

Econometric specification. We will estimate the relationship in the population of HIV/AIDS patients between the HIV drug utilization rate and both (1) the mortality rate and (2) the HIV hospitalization rate. The mortality analysis will be based on semiannual data for the period 1982:2-2001:2 $(\mathrm{N}=39)$. The hospitalization analysis will be based on annual data for the period 1993-2001 ( $\mathrm{N}=9)$.

We will examine the relationship between the logarithm of the mortality rate and the HIV drug utilization rate. This seems appropriate because the mortality rate is bounded between zero and one, and also because the mortality rate changed by a factor of 18 over the sample period. We don't use the logarithm of the HIV drug utilization rate because this variable was equal to zero before 1987. This semi-logarithmic specification is predicated on the hypothesis of diminishing returns: equal successive increases in the HIV drug utilization rate result in declining successive (absolute) reductions in the mortality rate. We show below that this specification seems to fit the data quite well.

The hospitalization rate changed far less during 1993-2001— by a factor of 3.8 - than the mortality rate changed during 1982:2-2001:2. It is also not bounded from above. We estimated models of both the hospitalization rate and the logarithm of the hospitalization rate. The estimates had similar implications; the former model seemed to fit the data slightly better, so we will report estimates of that model.

Many time series variables are characterized by unit roots. A variable y is said to have a unit root if $\pi=1$ in the autoregressive equation $y_{t}=\gamma+\pi y_{t-1}+\varepsilon_{t}$. As Greene [10, p. 846] observes, the regression of one variable characterized by a unit root on another variable characterized by a unit root "is virtually certain to produce a significant relationship, even if the 
two are, in fact, independent." He notes that under these circumstances, "the case for first differencing or detrending is compelling" [10, p. 847].

We estimated autoregressive equations for each of the three variables. The results are shown in Table 3. These estimates suggest that all three variables have, or nearly have, unit roots. (The estimate of $\pi$ in the $\log$ (mort) equation is significantly greater than one.) We will therefore estimate relationships between first differences, rather than levels, of the variables. Although the first difference of $\log$ (mort) is not stationary — the slope of the regression of $\Delta \log ($ mort $)$ on a time trend is negative and significant—-the first difference of the HIV drug utilization rate appears to be stationary. Greene [10, p. 844] observes that further differencing of time-series can increase rather than decrease autocorrelation.

Hence, we will estimate the following model of the mortality rate:

$$
\Delta \ln \left(\text { mort_rate }_{\mathrm{t}}\right)=\delta+\beta \Delta \mathrm{rx}_{\mathrm{t}}+\mathrm{v}_{\mathrm{t}}
$$

where

mort_rate $\mathrm{t}_{\mathrm{t}}=$ the crude mortality rate in period $\mathrm{t}$

$$
\mathrm{rx}_{\mathrm{t}}=\mathrm{HIV} \text { rx's per person living with AIDS in period } \mathrm{t}
$$

and $\Delta$ denotes the change from the previous period.

Eq. (1) embodies the assumption that changes in the rate of mortality decline are related only to contemporaneous changes in average drug utilization. It is quite possible that changes in mortality also depend on lagged changes in average drug utilization. To allow for this possibility, we will also estimate models like:

$$
\Delta \ln (\text { mort_rate })=\delta+\beta \Delta \mathrm{rx}_{\mathrm{t}}+\beta_{-1} \Delta \mathrm{rx}_{\mathrm{t}-1}+\beta_{-2} \Delta \mathrm{rx}_{\mathrm{t}-2}+\mathrm{v}_{\mathrm{t}}
$$

In this model, the long-run effect of drug utilization (i.e., the effect of a sustained increase in rx) is the sum of the coefficients, $\left(\beta+\beta_{-1}+\beta_{-2}\right)$. 
If drug utilization is exogenous with respect to mortality, changes in mortality should depend on current and past changes in drug utilization, but not on future changes. We can test the exogeneity of drug utilization by testing whether $\beta_{+1}=0$ in the model

$$
\Delta \ln (\text { mort_rate })=\delta+\beta_{+1} \Delta \mathrm{rx}_{\mathrm{t}+1}+\beta \Delta \mathrm{rx}_{\mathrm{t}}+\beta_{-1} \Delta \mathrm{rx}_{\mathrm{t}-1}+\beta_{-2} \Delta \mathrm{rx}_{\mathrm{t}-2}+\mathrm{v}_{\mathrm{t}}
$$

We will estimate the following model of the hospitalization rate:

$$
\Delta \operatorname{hosp}_{\mathrm{t}}=\delta+\beta \Delta \mathrm{rx}_{\mathrm{t}}+\mathrm{v}_{\mathrm{t}}
$$

where

hosp $\mathrm{p}_{\mathrm{t}}=$ inpatient hospital discharges for HIV infections per person living with AIDS in year t.

Since the hospitalization time series is extremely short, we will not investigate the lag structure of this relationship.

\section{Results}

Mortality results. Figure 4 shows the time series plots of $\Delta \ln \left(\right.$ mort_rate $\left._{t}\right)$ and $\Delta \mathrm{rx}_{\mathrm{t}}$. It suggests that changes in the rate of mortality decline were closely related to changes in average drug utilization.

Estimates of regressions of $\Delta \ln \left(\right.$ mort_rate $\left._{t}\right)$ on current, lagged, and/or future changes in drug utilization (eqs. 1-3) are reported in Table 4. All equations were estimated allowing for first-order serial correlation. The Durbin-Watson statistics indicate that the residuals are reasonably well-behaved.

Column 1 shows the regression of $\Delta \ln \left(\right.$ mort_rate $\left.{ }_{\mathrm{t}}\right)$ on $\Delta \mathrm{rx}_{\mathrm{t}}$ and $\Delta \mathrm{rx}_{\mathrm{t}-1}$. The coefficients on both variables are negative and highly significant. The magnitude of $\beta_{-1}$ is $50 \%$ larger than the magnitude of $\beta$, indicating thạt an increase in drug utilization reduces the mortality rate $50 \%$ 
more after six months than it does immediately. The sum of the coefficients is -0.10 : one additional prescription per person living with AIDS reduced the mortality rate by about $10 \%$. In column 2 we also include a time trend, to further guard against the possibility of spurious correlation. Although the trend is significant, its inclusion has virtually no effect on the estimated $\beta$ 's.

In column 3 we add $\Delta \mathrm{rx}_{\mathrm{t}-2}$ to the equation, but exclude the time trend. The coefficient on $\Delta \mathrm{rx}_{\mathrm{t}-2}$ is significant at the $6 \%$ level; adding it increases the magnitude of the sum of the $\beta$ 's by 19\%. In column 4 we include the time trend. The coefficient on $\Delta \mathrm{rx}_{\mathrm{t}-2}$ is significant at the $10 \%$ level; the sum of the $\beta$ 's is now -.11.

Finally, in column 5, we include $\Delta \mathrm{rx}_{\mathrm{t}+1}$, the change in drug utilization in the next period. The coefficient on $\Delta \mathrm{rx}_{\mathrm{t}+1}$ is far from statistically significant ( $\mathrm{p}$-value $=0.66$ ), lending support to the exogeneity of drug utilization.

These estimates can be used to calculate how much higher the mortality rate would have been in 2001 if the drug utilization rate had not increased up until that point. The calculations are summarized in Table 5. Between 1993 and 2001, the average semiannual rate of drug utilization increased by 6.5 , from 2.9 to 9.4 prescriptions. The estimates in column 4 imply that this reduced $\ln$ (mort_rate) by 0.71 . In other words, $\ln$ (mort_rate ${ }_{2001}$ ) would have been 0.71 higher if the rate of drug utilization had not increased since 1993; mort_rate ${ }_{2001}$ would have been $2.03(=\exp (0.71))$ times as high as it actually was. The actual value of mort_rate ${ }_{2001}$ was $3.8 \%$, so the predicted value, if drug utilization had not increased after 1993 , is $7.7 \%(=2.03 * 3.8 \%)$. As discussed above, life expectancy may be approximated by the reciprocal of the mortality rate. This implies that actual life expectancy in 2001 was $13.4(=26.3-12.9)$ years higher than it would have been if the drug utilization rate had not increased from its 1993 level. These data suggest that about $60 \%$ of the total 22.6-year increase in life expectancy during 1993-2001 is attributable to the increase in drug utilization. 
Hospitalization results. Figure 5 shows annual data on changes in drug and hospital utilization during 1994-2002. This chart suggests that there is a strong inverse relationship between these variables.

Estimates of eq. (4) are presented in Table 6. Estimates of $\beta$ and $\delta$ are significantly different from zero, suggesting that the hospitalization rate is inversely related to the drug utilization rate, and that the hospitalization rate would have declined, even if the drug utilization rate had not increased. From 1993 to 2001, the semiannual drug utilization rate increased by 6.33 (from 2.88 to 9.21). The estimates imply that this caused hospital utilization to decline by .25 to .29 discharges/year. (The total decline in hospital utilization was 0.75 discharges per year).

Now we will estimate the effect of increased HIV drug utilization and expenditure on overall medical expenditure per year and over the course of the patient's remaining life. First we will estimate actual expenditure per HIV patient in 2000. Then we will estimate what expenditure per patient would have been in 2000 in the absence of any increase in drug utilization after 1993.

Data on average inpatient and outpatient utilization and costs in 2000 are available from HIVnet [11]. Data on average prescription drug utilization and costs in 2000 are calculated in Table 1. These figures are summarized in Table 7. As shown in Table 1, from 1993 to 2000, mean drug expenditure per patient increased by $\$ 7356$ (in 2001 dollars). This was due to increases in both the average number and average price of prescriptions. We estimate that the 1993-2000 increase in drug utilization reduced the average number of hospital admissions per HIV patient in 2000 by 0.33 . (In the absence of the drug utilization increase, the number of hospital admissions (like the number of deaths) would have been double what it actually was.) Therefore the 1993-2000 increase in drug utilization reduced mean hospital expenditure in 2000 by $\$ 3826$. About $52 \%(=\$ 3826 / \$ 7356)$ of the increase in HIV drug expenditure appears to have been offset by a reduction in hospital expenditure.

The increase in drug utilization may also have reduced outpatient costs: between 1991 and 2000, the average annual number of outpatient visits per HIV patient declined from 41.0 to 
6.4. (The 1991 figure was calculated from the AIDS Cost and Services Utilization Survey.) But time-series data on outpatient visits are not available, so it is hard to know how much of this decline can be attributed to increased drug utilization. For the moment, assume that increased drug utilization reduced hospital expenditure, but not outpatient expenditure.

In this case, we predict that, if drug utilization had not increased from its 1993 level, average medical expenditure in 2000 would have been $\$ 10,247(=\$ 13,777-\$ 7356+\$ 3826)$. As Table 8 shows, by combining these annual expenditure figures with the life expectancy figures derived earlier, we can compute actual vs. counterfactual lifetime medical expenditure. In 2000, average medical expenditure per HIV patient was $\$ 13,777$, and his life expectancy was 26.3 years, so (undiscounted) lifetime medical expenditure is projected to be $\$ 362$ thousand. If drug utilization had not increased from its 1993 level, average medical expenditure in 2000 would have been $\$ 3530$ lower, and life expectancy would have been 12.9 years, so lifetime medical expenditure would have been $\$ 132$ thousand. Medical cost per additional life-year is $\$ 17,175$ (= $\$ 230,140 / 13.4)$.

\section{Discussion}

This paper has assessed the impact of increased utilization of HIV drugs on the life expectancy, annual medical expenditure, and lifetime medical expenditure of HIV/AIDS patients, using aggregate (U.S. national-level) data for the period 1982-2001.

Estimates of a mortality model implied that actual life expectancy in 2001 was 13.4 years higher than it would have been if the drug utilization rate had not increased from its 1993 level. About $60 \%$ of the total 22.6-year increase in life expectancy during 1993-2001 is attributable to the increase in drug utilization.

Estimates of a model of hospital discharges implied that increased utilization of HIV drugs caused hospital utilization to decline by .25 to .29 discharges per person per year. About 
one-third of the total decline in hospital utilization during 1993-2001 is attributable to the increase in drug utilization, and 52\% of the increase in HIV drug expenditure appears to have been offset by a reduction in hospital expenditure.

Two caveats apply to our hospitalization estimates. First, the HCUP data on HIV hospital admissions may not be completely reliable: HIV hospital admissions were geographically concentrated in a few major urban centers, particularly in earlier years of the HIV epidemic, when HCUP also included data from fewer states. Second, due to measurement error in estimating the number of HIV patients, our estimate of the reduction in hospital discharges is likely to be conservative. Suppose that the number of patients living with AIDS is overestimated in year $\mathrm{t}$ (e.g. due to failure of AIDSPIDS to distinguish between people who remain alive and people who have died but whose date of death is unknown). This would cause both hosp $\mathrm{p}_{\mathrm{t}}$ and $\mathrm{rx}_{\mathrm{t}}$ to be underestimated in year $\mathrm{t}$, and induce a positive correlation between these two series.

In 2000, average medical expenditure per HIV patient was $\$ 13,777$, and his life expectancy was 26.3 years, so (undiscounted) lifetime medical expenditure is projected to be $\$ 362$ thousand. If drug utilization had not increased from its 1993 level, average medical expenditure in 2000 would have been $\$ 3530$ lower, and life expectancy would have been 12.9 years, so lifetime medical expenditure would have been $\$ 132$ thousand. Medical cost per additional life-year is $\$ 17,175$.

Increased drug utilization may have reduced outpatient as well as inpatient costs. If there would have been twice as many outpatient visits in 2000 absent the post-1993 increase in drug utilization—12.8 rather than 6.4 visits per person—we estimate that cost per life-year is $\$ 16,007$ instead of $\$ 17,175$.

Our estimates of mean lifetime expenditure (both actual and predicted under 1993 drug utilization) are not discounted. The estimates of Duggan and Evans are also not discounted. To produce accurate estimates of discounted expenditure, one needs to project the course (or growth rate) of future annual medical expenditure over a patient's remaining life, which is difficult to do. 
If the growth rate of annual medical expenditure exceeds the discount (interest) rate, then discounted expenditure exceeds undiscounted expenditure. If the growth rate is lower than the discount rate, then discounted expenditure is lower than undiscounted expenditure. It seems to us that the growth rate could be either higher or lower than the discount rate, so that undiscounted estimates need not either overstate or understate discounted estimates.

These estimates are similar to those obtained in previous studies based on completely different methods. Freedberg et al's estimate of the (discounted) cost of three-drug therapy per quality-adjusted year of life gained, derived from a mathematical simulation model of HIV disease, ranged from $\$ 13,000$ to $\$ 23,000$. Duggan and Evans' (2005) estimate of medical cost per additional life-year, derived from individual-level pharmacy and medical claims data, was $\$ 23,000$. Both authors note that treatments that cost $\$ 23,000$ per life-year gained are widely considered to be cost-effective. Murphy and Topel [12] argue that the average value of a U.S. statistical life may be on the order of $\$ 150,000$.

The overall consistency of our estimates with those from previous studies suggests that analysis of aggregate data may be a useful alternative or additional approach to evaluating the cost-effectiveness of new treatments.

Our estimates, and those by previous authors, do not account for a potentially important benefit of new HIV drugs: increased ability to work. The data shown in Table 9, computed from the 1996-2001 waves of the Medical Expenditure Panel Survey [13], indicate that the percent of people with HIV who were unable to work due to illness has been declining. The difference in percentages is significant at the $5.3 \%$ level. Moreover, the measured improvement in ability to work may be underestimated because there were probably more early diagnoses of HIV between 1996 and 1998, possibly leading to a higher proportion of HIV-infected individuals in the MEPS who knew that they were HIV-infected, were asymptomatic and were still able to work. It is likely that increased drug utilization reduced inability to work among HIV patients. 
The HIV drugs already approved by the FDA may be either less or more cost-effective in the future than they have been in the past. Increasing resistance to these drugs would clearly reduce their cost-effectiveness. On the other hand, the patents on these drugs will eventually expire. When they do, the cost-effectiveness of these drugs will increase dramatically, since drug prices typically decline by about $80 \%$ following patent expiration. However, the impact of patent expirations on total HIV drug expenditures is likely to be reduced as newer drugs that are considered more effective or convenient or that have fewer side effects replace drugs closer to patent expiration.

Forecasting the future trajectory of HIV/AIDS treatment and outcomes is difficult. As the philosopher Soren Kierkegaard observed, "life must be lived forwards, but can only be understood backwards." But there is reason to expect further progress in the future. Just days ago the FDA approved a new product that may have a significant impact. On July 12, 2006, the FDA approved Atripla Tablets, a fixed-dose combination of three widely-used antiretroviral drugs, in a single tablet taken once a day, alone or in combination with other antiretroviral products for the treatment of HIV-1 infection in adults. Atripla, the first one-pill, once-a-day product to treat HIV/AIDS, combines the active ingredients of Sustiva (efavirenz), Emtriva (emtricitabine) and Viread (tenofovir disoproxil fumarate). Bristol-Myers Squibb and Gilead Sciences have formed a joint venture to commercialize Atripla in the United States. The collaboration is the first of its kind in the field of HIV/AIDS. In certain territories, Merck holds the rights to efavirenz. All three companies will work together to ensure the product is available to patients and physicians. "The approval of Atripla simplifies the treatment regimen for HIV-1 infected adults, and will potentially improve the ability of patients to adhere to treatment resulting in long-term effective control of HIV-1. This offers a particularly important advantage for patients in many countries that are most affected by the AIDS epidemic and will also have a major impact in the U.S.," said Dr. Andrew C. von Eschenbach, the Acting Commissioner of Food and Drugs. 
HIV/AIDS continues to be an active area of pharmaceutical R\&D. According to the U.S. government's ClinicalTrials.gov website, which provides regularly updated information about federally and privately supported clinical research in human volunteers, at present, there are 557 trials of HIV/AIDS drugs currently recruiting or planning to recruit patients; 1753 trials have been completed or are no longer recruiting patients. 


\section{References}

[1] Food and Drug Administration, Office of Special Health Issues, Drugs Used in the Treatment of HIV Infection, http://www.fda.gov/oashi/aids/virals.html

[2] Kenneth A Freedberg, Elena Losina, Milton C Weinstein, A David Paltiel, et al. "The cost effectiveness of combination antiretroviral therapy for HIV Disease," The New England Journal of Medicine. Boston: Mar 15, 2001.Vol. 344, Iss. 11; pg. 824-31.

[3] Duggan, Mark G., and William N. Evans, "Estimating the Impact of Medical Innovation: The Case of HIV Antiretroviral Treatments," NBER Working Paper No. 11109, February 2005, http://www.nber.org/papers/w11109.

[4] Centers for Disease Control, AIDS Public Information Data Set, http://www.cdc.gov/hiv/software/apids.htm

[5] Centers for Disease Control,, AIDS Public Information Data Summary, http://wonder.cdc.gov/wonder/help/aids.html

[6] Arias E. United States life tables, 2002. National vital statistics reports; vol 53 no 6.

Hyattsville, Maryland: National Center for Health Statistics. 2004.

http://www.cdc.gov/nchs/data/nvsr/nvsr53/nvsr53 06.pdf

[7] Centers for Disease Control \& Prevention, National Center for HIV, STD, and TB Prevention, Divisions of HIV/AIDS Prevention, Surveillance Branch, http://www.cdc.gov/HIV/graphics/mortalit.htm

[8] Lai DJ, Tarwater PM, Hardy RJ, "Measuring the impact of HIV/AIDS, heart disease and malignant neoplasms on life expectancy in the USA from 1987 to 2000.” Public Health. 2006 Jun;120(6):486-92.

[9] HCUPnet, Healthcare Cost and Utilization Project. Agency for Healthcare Research and Quality, Rockville, MD. http://www.ahrq.gov/HCUPnet/ 
[10] Greene, William H., Econometric Analysis, Third Edition (Upper Saddle River, NJ: PrenticeHall, 1997).

[11] HIVnet. HIV Resource Utilization Data Coordinating Center (DCC) project. February 2003. Agency for Healthcare Research and Quality, Rockville, MD.

http://www.ahrq.gov/data/HIVnet.htm

[12] Murphy, Kevin M., and Robert H. Topel, “The Economic Value of Medical Research ,” in Measuring the Gains from Medical Research: An Economic Approach, ed. by Kevin M. Murphy and Robert H. Topel (Chicago: University of Chicago Press, 2003).

[13] Medical Expenditure Panel Survey, Agency for Healthcare Research and Quality, Rockville, MD. http://www.meps.ahrq.gov 
Figure 1

Annual mortality rate and \% change in annual mortality rate
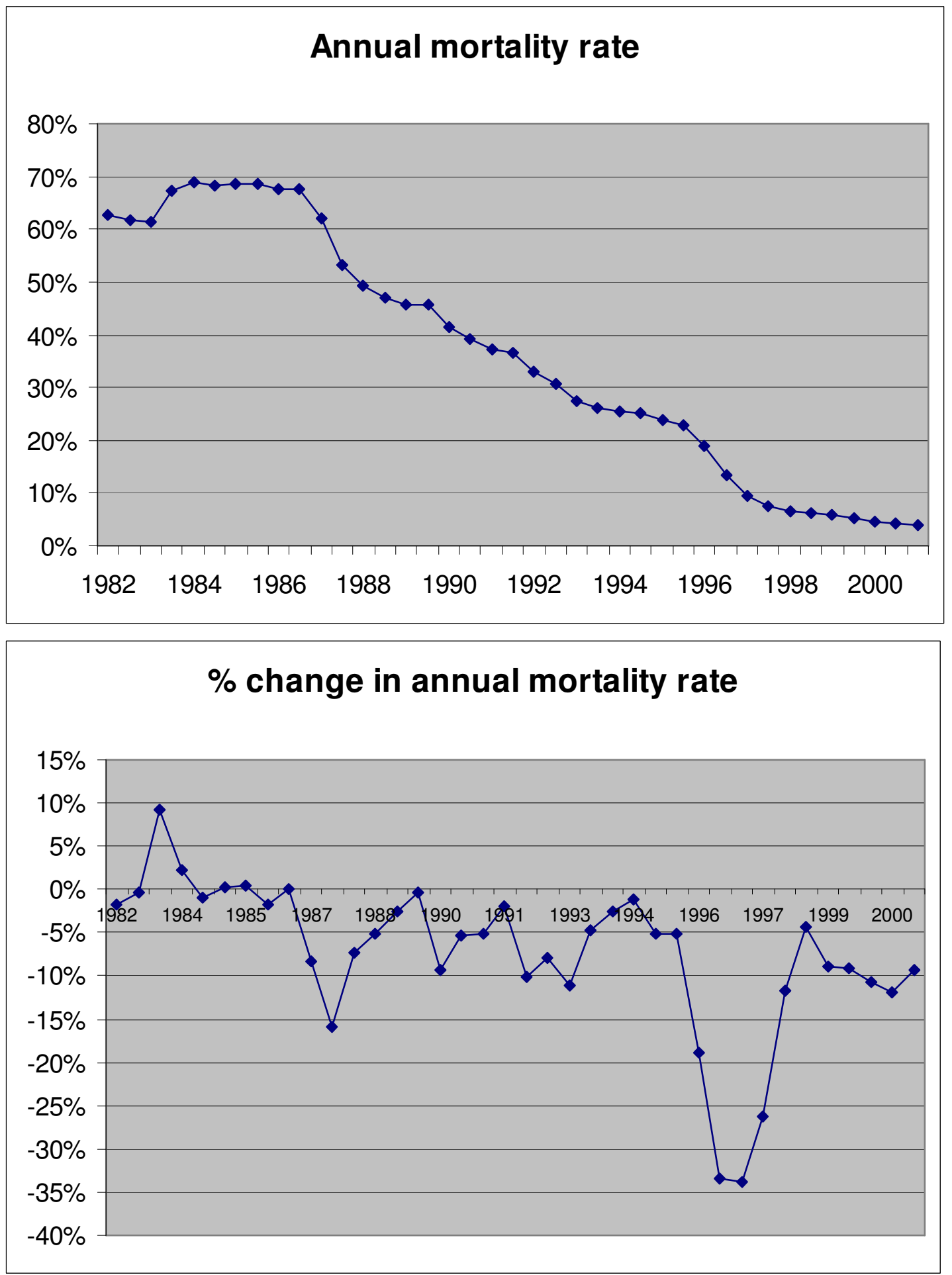
Figure 2

Survival functions: 1993 vs. 2000

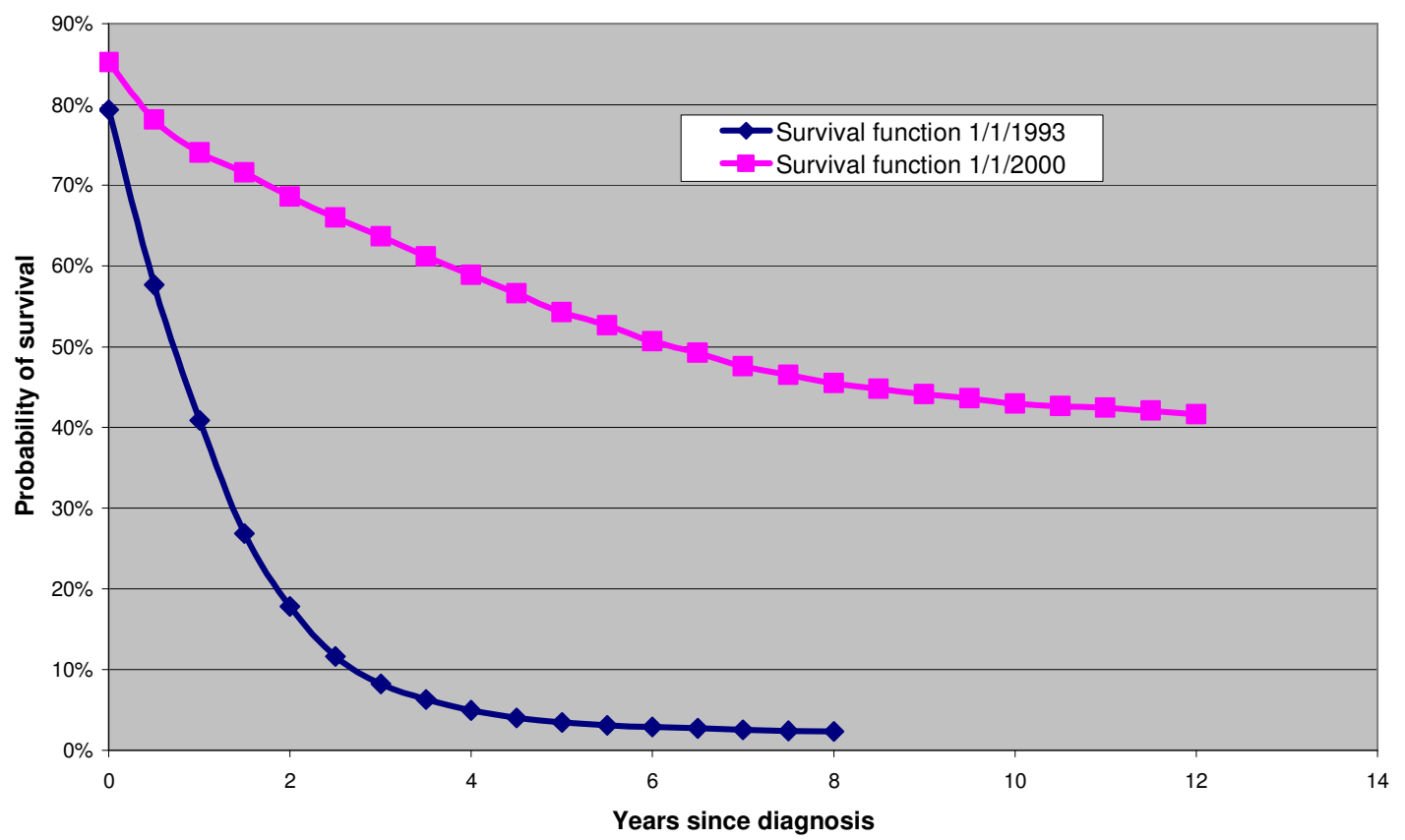

Figure 3

No. of HIV Rx's per person living with HIVIAIDS

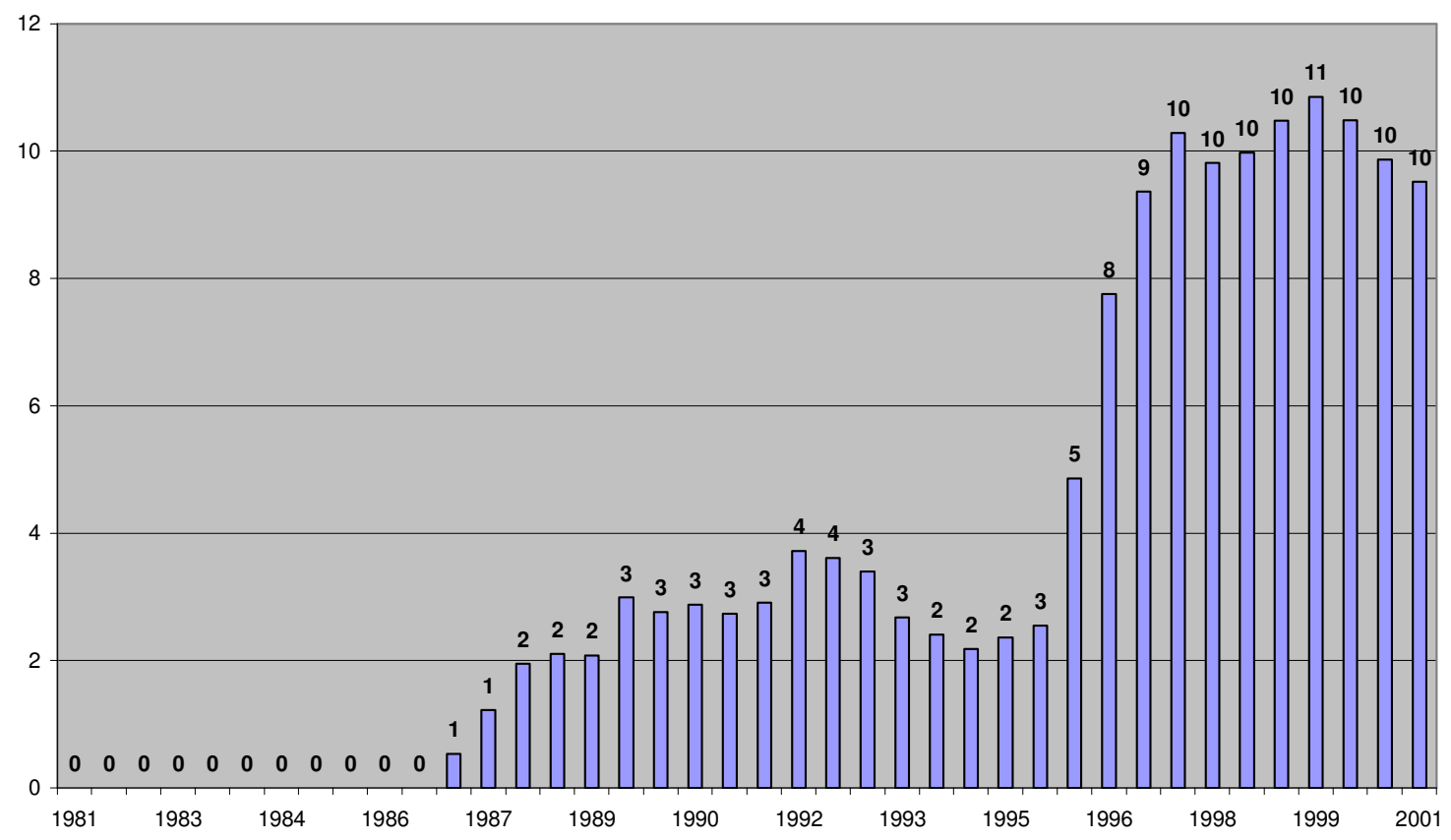


Figure 4

Change in average drug utilization and $\%$ change in mortality rate

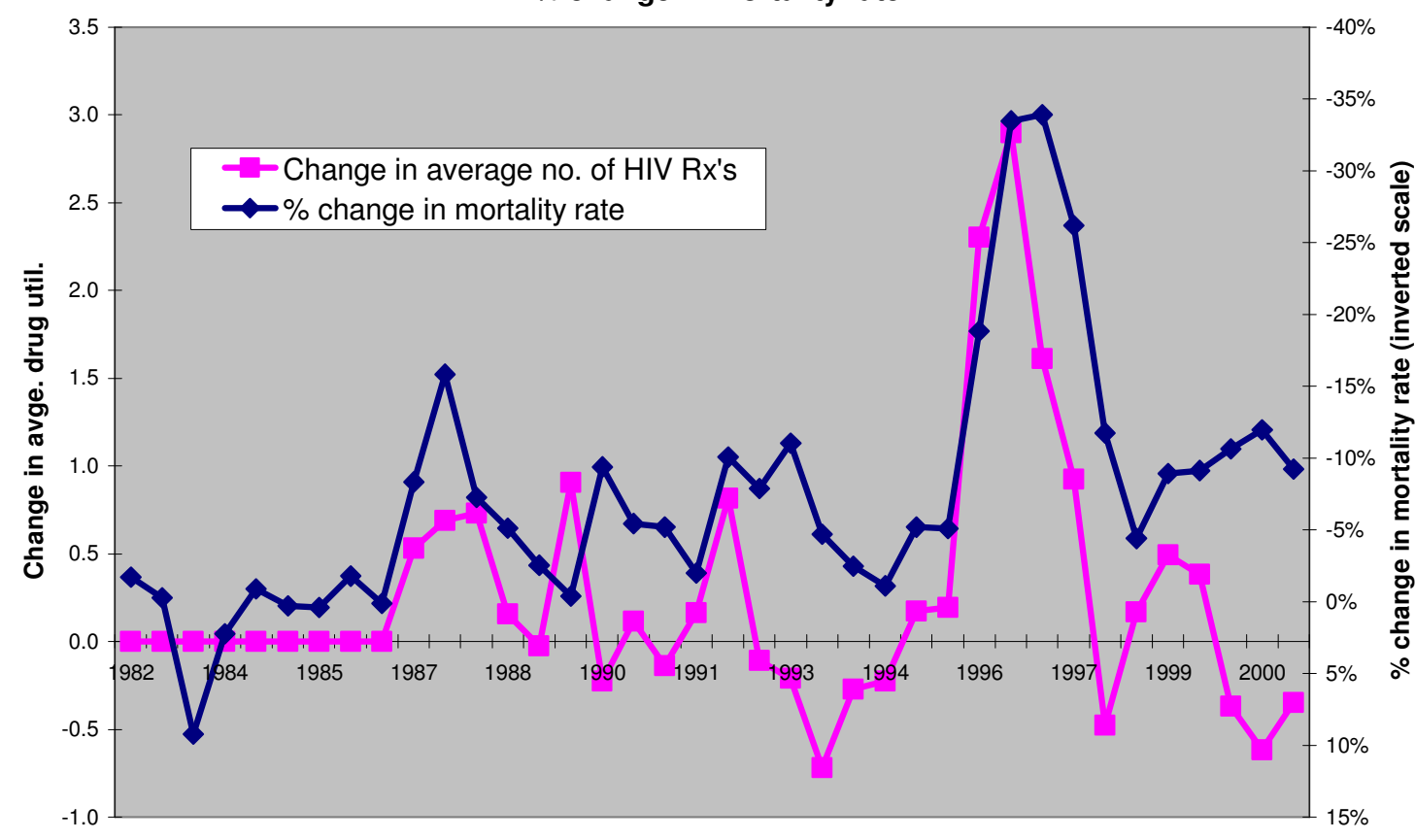

Figure 5

Changes in drug and hospital utilization

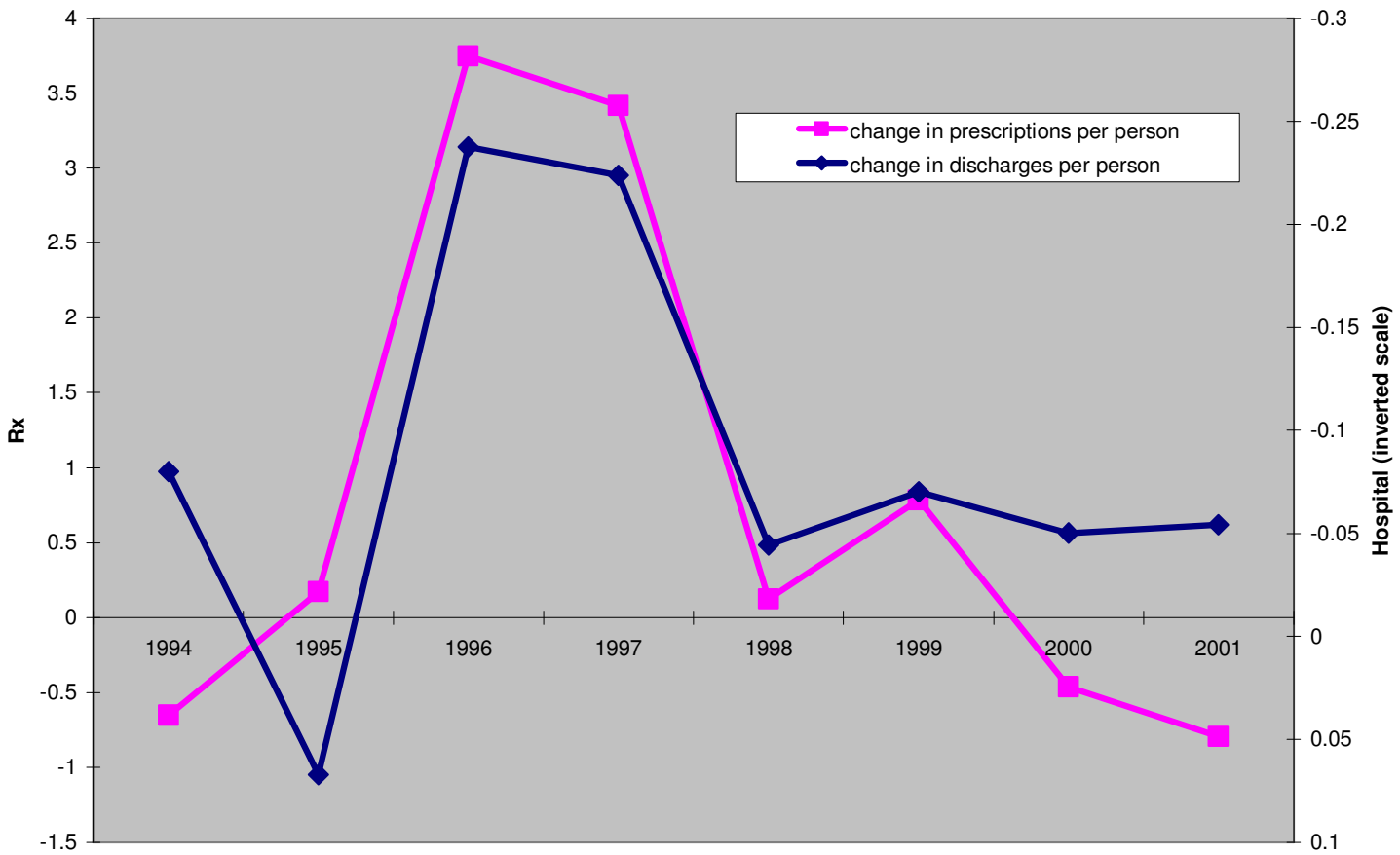


Table 1

HIV drug expenditure, quantities, and prices, 1987-2003

\begin{tabular}{|c|c|c|c|c|c|c|c|c|c|}
\hline Year & $\begin{array}{l}\text { Total expend. } \\
\text { on HIV drugs }\end{array}$ & $\begin{array}{c}\text { Total no. } \\
\text { of HIV } \\
\text { Rx's }\end{array}$ & $\begin{array}{c}\text { Avge. } \\
\text { price } \\
\text { of } \\
\text { HIV } \\
\text { Rx }\end{array}$ & $\begin{array}{c}\text { CPI } \\
(2001 \\
= \\
1.00)\end{array}$ & $\begin{array}{c}\begin{array}{c}\text { Avge. } \\
\text { price } \\
\text { of }\end{array} \\
\text { HIV } \\
\text { Rx in } \\
2001 \\
\$\end{array}$ & $\begin{array}{c}\text { Avge. no. } \\
\text { of AIDS } \\
\text { survivors }\end{array}$ & $\begin{array}{c}\text { Avge. } \\
\text { no. of } \\
\text { rx's per } \\
\text { survivor }\end{array}$ & $\begin{array}{c}\text { HIV } \\
\text { drug } \\
\text { expend. } \\
\text { per } \\
\text { survivor }\end{array}$ & $\begin{array}{c}\text { HIV } \\
\text { drug } \\
\text { expend. } \\
\text { per } \\
\text { survivor } \\
\text { in } 2001 \\
\$\end{array}$ \\
\hline 1987 & $\$ 21,645,000$ & 44,000 & $\$ 492$ & 0.64 & $\$ 767$ & 24,076 & 1.8 & $\$ 899$ & $\$ 1,402$ \\
\hline 1988 & $\$ 94,413,000$ & 155,000 & $\$ 609$ & 0.67 & $\$ 912$ & 37,825 & 4.1 & $\$ 2,496$ & $\$ 3,737$ \\
\hline 1989 & $\$ 120,129,000$ & 274,000 & $\$ 438$ & 0.70 & $\$ 626$ & 52,989 & 5.2 & $\$ 2,267$ & $\$ 3,238$ \\
\hline 1990 & $\$ 118,242,000$ & 395,000 & $\$ 299$ & 0.74 & $\$ 406$ & 69,566 & 5.7 & $\$ 1,700$ & $\$ 2,303$ \\
\hline 1991 & $\$ 128,594,000$ & 510,000 & $\$ 252$ & 0.77 & $\$ 328$ & 90,155 & 5.7 & $\$ 1,426$ & $\$ 1,855$ \\
\hline 1992 & $\$ 219,567,933$ & 881,954 & $\$ 249$ & 0.79 & $\$ 314$ & 120,792 & 7.3 & $\$ 1,818$ & $\$ 2,295$ \\
\hline 1993 & $\$ 215,463,941$ & 960,195 & $\$ 224$ & 0.82 & $\$ 275$ & 156,769 & 6.1 & $\$ 1,374$ & $\$ 1,684$ \\
\hline 1994 & $\$ 187,382,573$ & 854,331 & $\$ 219$ & 0.84 & $\$ 262$ & 185,057 & 4.6 & $\$ 1,013$ & $\$ 1,210$ \\
\hline 1995 & $\$ 243,987,768$ & $1,015,081$ & $\$ 240$ & 0.86 & $\$ 279$ & 205,556 & 4.9 & $\$ 1,187$ & $\$ 1,379$ \\
\hline 1996 & $\$ 730,378,758$ & $2,870,875$ & $\$ 254$ & 0.89 & $\$ 287$ & 226,366 & 12.7 & $\$ 3,227$ & $\$ 3,642$ \\
\hline 1997 & $\$ 1,301,074,673$ & $4,965,342$ & $\$ 262$ & 0.91 & $\$ 289$ & 251,658 & 19.7 & $\$ 5,170$ & $\$ 5,705$ \\
\hline 1998 & $\$ 2,122,480,573$ & $5,497,208$ & $\$ 386$ & 0.92 & $\$ 420$ & 277,265 & 19.8 & $\$ 7,655$ & $\$ 8,317$ \\
\hline 1999 & $\$ 2,611,440,838$ & $6,414,291$ & $\$ 407$ & 0.94 & $\$ 433$ & 300,130 & 21.4 & $\$ 8,701$ & $\$ 9,249$ \\
\hline 2000 & $\$ 2,830,025,097$ & $6,551,441$ & $\$ 432$ & 0.97 & $\$ 444$ & 321,948 & 20.3 & $\$ 8,790$ & $\$ 9,040$ \\
\hline 2001 & $\$ 3,293,652,795$ & $6,369,758$ & $\$ 517$ & 1.00 & $\$ 517$ & 337,783 & 18.9 & $\$ 9,751$ & $\$ 9,751$ \\
\hline 2002 & $\$ 3,608,326,800$ & $6,923,830$ & $\$ 521$ & 1.02 & $\$ 513$ & & & & \\
\hline 2003 & $\$ 3,962,475,549$ & $7,549,933$ & $\$ 525$ & 1.04 & $\$ 505$ & & & & \\
\hline
\end{tabular}

Sources: IMS; AIDSPIDS 


\section{Table 2}

Hospitalizations in Major Diagnostic Category 25 (HIV Infections), 1993-2002

\begin{tabular}{|l|r|}
\hline Year & Total number of discharges \\
\hline 1993 & 159,566 \\
\hline 1994 & 167,599 \\
\hline 1995 & 198,752 \\
\hline 1996 & 163,115 \\
\hline 1997 & 124,120 \\
\hline 1998 & 123,250 \\
\hline 1999 & 111,548 \\
\hline 2000 & 102,910 \\
\hline 2001 & 89,931 \\
\hline 2002 & 92,791 \\
\hline
\end{tabular}

Source: http://hcup.ahrq.gov/HCUPnet.asp 
Table 3

Estimates of autoregressive equations for the three variables

\begin{tabular}{|l|c|c|c|c|}
\hline $\mathrm{y}$ & $\log (\mathrm{mort})$ & $\mathrm{rx}$ & hosp & rx \\
\hline$\pi$ & 1.03939 & 1.00116 & 0.90565 & 0.81394 \\
\hline std. err. & 0.013 & 0.03163 & 0.14806 & 0.18351 \\
\hline t-statistic & 79.97 & 31.65 & 6.12 & 4.44 \\
\hline p-value & $<.0001$ & $<.0001$ & 0.0009 & 0.0044 \\
\hline frequency & semiannual & semiannual & annual & annual \\
\hline sample & $1982: 2-$ & $1982: 2-$ & $1993-$ & $1993-$ \\
period & $2001: 2$ & $2001: 2$ & 2001 & 2001 \\
\hline
\end{tabular}


Table 4

Estimates of models of $\Delta \ln \left(\right.$ mort_rate $\left.{ }_{t}\right)$

\begin{tabular}{|c|c|c|c|c|c|c|}
\hline Column & & 1 & 2 & 3 & 4 & 5 \\
\hline \multicolumn{7}{|l|}{$\Delta \mathrm{rx}_{\mathrm{t}+1}$} \\
\hline & estimate & & & & & 0.004535 \\
\hline & std. err. & & & & & 0.0102 \\
\hline & t-stat & & & & & 0.44 \\
\hline & p-value & & & & & 0.6604 \\
\hline \multirow{2}{*}{\multicolumn{7}{|c|}{$\Delta \mathrm{rx}_{\mathrm{t}}$}} \\
\hline & & & & & & \\
\hline & estimate & -0.0405 & -0.0352 & -0.0409 & -0.0381 & -0.0408 \\
\hline & std. err. & 0.012 & 0.0105 & 0.0114 & 0.009759 & 0.0115 \\
\hline & t-stat & -3.37 & -3.34 & -3.58 & -3.90 & -3.56 \\
\hline & $\mathrm{p}$-value & 0.0019 & 0.0021 & 0.0011 & 0.0005 & 0.0013 \\
\hline \multirow{2}{*}{\multicolumn{7}{|c|}{$\Delta \mathrm{rX}_{\mathrm{t}-1}$}} \\
\hline & & & & & & \\
\hline & std. err. & 0.012 & 0.0107 & 0.0117 & 0.0109 & 0.0115 \\
\hline & t-stat & -4.99 & -5.98 & -4.70 & -4.91 & -4.81 \\
\hline & p-value & $<0.0001$ & $<0.0001$ & $<0.0001$ & $<0.0001$ & $<0.0001$ \\
\hline \multicolumn{7}{|l|}{$\Delta \mathrm{rx}_{\mathrm{t}-2}$} \\
\hline & estimate & & & -0.0226 & -0.0175 & -0.0179 \\
\hline & std. err. & & & 0.0116 & 0.0101 & 0.0107 \\
\hline & t-stat & & & -1.95 & -1.74 & -1.67 \\
\hline & p-value & & & 0.0595 & 0.092 & 0.1062 \\
\hline \multicolumn{7}{|l|}{ time (measured in days) } \\
\hline & estimate & & $\begin{array}{c}- \\
0.000015\end{array}$ & & $\begin{array}{c}- \\
0.000016\end{array}$ & $\begin{array}{c}- \\
0.000015\end{array}$ \\
\hline & std. err. & & $3.27 \mathrm{E}-06$ & & $3.47 \mathrm{E}-06$ & $3.49 \mathrm{E}-06$ \\
\hline & t-stat & & -4.70 & & -4.69 & -4.31 \\
\hline & $\mathrm{p}$-value & & $<0.0001$ & & $<0.0001$ & 0.0002 \\
\hline \multicolumn{7}{|l|}{ Intercept } \\
\hline & estimate & -0.0577 & 0.122 & -0.051 & 0.1379 & 0.1274 \\
\hline & std. err. & 0.0126 & 0.0381 & 0.013 & 0.0406 & 0.0406 \\
\hline & t-stat & -4.59 & 3.20 & -3.93 & 3.40 & 3.14 \\
\hline & $\mathrm{p}$-value & $<0.0001$ & 0.003 & 0.0004 & 0.0019 & 0.0039 \\
\hline sum of current $\&$ lagged $\beta$ 's & & -0.1006 & -0.099 & -0.1185 & -0.1093 & -0.1141 \\
\hline Durbin-Watson statistic & & 1.8461 & 1.8209 & 1.8729 & 1.9308 & 1.8371 \\
\hline $\mathrm{R}^{2}$ & & 0.7853 & 0.8392 & 0.8173 & 0.872 & 0.8767 \\
\hline
\end{tabular}


Table 5

Actual vs. predicted mortality rates and life expectancy

\begin{tabular}{|l|r|r|}
\hline & mortality rate & life expectancy \\
\hline 2001 actual & $3.80 \%$ & 26.3 \\
\hline 2001 predicted, given 1993 drug util rate & $7.70 \%$ & 12.9 \\
\hline 1993 actual & $27.00 \%$ & 3.7 \\
\hline
\end{tabular}

Table 6

Estimates of eqs. (4)

\begin{tabular}{|l|c|}
\hline Parameter estimates & \\
\hline $\boldsymbol{\beta}$ & -0.046 \\
\hline Standard Error & 0.013 \\
\hline t Stat & -3.583 \\
\hline P-value & 0.012 \\
\hline & \\
\hline $\boldsymbol{\delta}$ & -0.050 \\
\hline Standard Error & 0.024 \\
\hline t Stat & -2.119 \\
\hline P-value & 0.078 \\
\hline & \\
\hline & \\
\hline & \\
\hline & \\
\hline & \\
\hline & \\
\hline Regression Statistics & \\
\hline Multiple R & 0.826 \\
\hline R Square & 0.682 \\
\hline Adjusted R Square & 0.628 \\
\hline Standard Error & 0.061 \\
\hline Observations & 8 \\
\hline & \\
\hline Degrees offreedom & 7 \\
\hline Regression & \\
\hline Residual & \\
\hline Total & \\
\hline & \\
\hline & \\
\hline & \\
\hline & \\
\hline & \\
\hline & \\
\hline & \\
\hline & \\
\hline & \\
\hline & \\
\hline & \\
\hline & \\
\hline & \\
\hline & \\
\hline & \\
\hline & \\
\hline & \\
\hline
\end{tabular}


Table 7

Average inpatient, outpatient and drug utilization and costs in 2000

\begin{tabular}{|l|r|r|r|}
\hline Category & \multicolumn{1}{|l|}{ mean no. of events } & mean expend. per event & mean expend. \\
\hline inpatient & 0.32 & $\$ 11,722$ & $\$ 3,773$ \\
\hline outpatient & 6.42 & $\$ 189$ & $\$ 1,213$ \\
\hline drug & 20.3 & $\$ 432$ & $\$ 8,790$ \\
\hline total & & & $\$ 13,777$ \\
\hline
\end{tabular}

Table 8

Actual vs. counterfactual lifetime medical expenditure

\begin{tabular}{|l|c|c|c|}
\hline & $\begin{array}{c}\text { mean expend-- } \\
\text { annual }\end{array}$ & life expectancy & $\begin{array}{c}\text { mean expend-- } \\
\text { lifetime }\end{array}$ \\
\hline 2000 actual & $\$ 13,777$ & 26.3 & $\$ 362,325$ \\
\hline $\begin{array}{l}2000 \text { predicted } \\
\text { if 1993 drug util. }\end{array}$ & $\$ 10,247$ & 12.9 & $\$ 132,185$ \\
\hline difference & $\$ 3,530$ & 13.4 & $\$ 230,140$ \\
\hline
\end{tabular}

Table 9

Percent of people with HIV who were unable to work due to illness

\begin{tabular}{|l|c|c|}
\hline & $\begin{array}{c}\text { \% of persons with HIV who } \\
\text { were unable to work } \\
\text { because of illness }\end{array}$ & $\mathrm{N}$ \\
\hline $1996-1998$ & $54.3 \%$ & 70 \\
\hline $1999-2001$ & $38.0 \%$ & 71 \\
\hline
\end{tabular}

